\title{
¿CLASES SOCIALES O STATUS? LAS RELACIONES SOCIALES EN LA ANTIGÜEDAD DESDE KARL MARX*
}

DOI: http://dx.doi.org/10.17981/juridcuc.11.1.2015.11

Recibido: 11 de Mayo de 2015 / Revisado: 22 de Julio de 2015 / Aceptado: 23 de Julio de 2015

\author{
Alejandro Blanco Zúñiga ${ }^{* *}$ - Miguel Camilo Espinosa Ardila*** \\ Universidad del Atlántico \\ Puede citar el presente artículo así: / To reference this article: \\ Blanco, A. \& Espinosa, M. (2015). ¿Clases sociales o status? Las relaciones sociales en la Antigüedad desde \\ Karl Marx. Jurídicas CUC, 11(1), 243-266. doi: http://dx.doi.org/10.17981/juridcuc.11.1.2015.11
}

\section{Resumen}

Las dificultades para interpretar las sociedades antiguas desde la concepción materialista de la historia están relacionadas con la incomprensión del método de Marx. El autor comprendía que las categorías económicas de la sociedad capitalista no pueden ser aplicadas en forma directa para sociedades anteriores, como en el caso del concepto de capital, dado que ello conduce a un falseamiento de las relaciones históricas. Respecto del concepto de clase social, Marx lo analiza de acuerdo a niveles de abstracción, íntimamente ligado al método dialéctico. De esta manera, al momento de analizar las sociedades antiguas utilizando el concepto de clase social, hay que tener presente los niveles de abstracción que permitirán develar las relaciones sociales desde el punto de vista de la totalidad. En este sentido, los conceptos alternativos de Moses Finley (órdenes y status) no se encuentran por fuera del concepto de clase social, sino que son concreciones del análisis.

\section{Palabras clave:}

Karl Marx, clases sociales, niveles de abstracción, método dialéctico, Moses Finley, órdenes, status.

\footnotetext{
* Articulo de reflexión realizado con recursos propios de los autores

** Egresado del programa de Historia en la Universidad del Atlántico, magister en Educación de la Universidad del Norte, doctorando en filosofía política de la Universidad Urbe de Venezuela. Correo electrónico: alejov84@hotmail.com.

**** Egresado no graduado del programa de Derecho diurno en la Universidad del Atlántico. Correo electrónico: miguelche1@hotmail.com.
} 


\section{SOCIAL CLASSES OR STATUS? SOCIAL RELATIONSHIPS IN ANTIQUITY: KARL MARX'S METHOD}

\section{Abstract}

The struggles in the interpretation of ancient societies from the materialistic conception of history are related to the misunderstanding of Marx's method. The author understood that economic categories of capitalist society could not be applied directly to previous societies, as in the case of the concept of capital, since this leads to a distortion of the historical relations. Regarding the concept of social class, Marx analyzed it according to levels of abstraction, closely linked to the dialectical method. Thus, when analyzing ancient societies using the concept of social class, it is of great importance to remember the levels of abstraction that will reveal the social relationships from the point of view of totality. In this sense, alternative concepts of Moses Finley (orders and status) are not out of the concept of social class but specificities of the analysis.

\section{Keywords:}

Karl Marx, Social Class, Abstraction Levels, Dialectical Method, Moses Finley, Orders, Status 


\section{INTRODUCCIÓN}

Se ha insistido con frecuencia sobre la dificultad, e inclusive, la imposibilidad de hacer uso del concepto de clase social (en el sentido que le dieron Karl Marx y Friedrich Engels) para interpretar las sociedades antiguas. Quienes afirman lo anterior llegan al mismo punto de sus más implacables defensores, de aquellos que se aferran al sistema elaborado por Marx: toda la riqueza presente en su obra se pierde por la incomprensión del método.

El trabajo implica develar aspectos metodológicos que siempre estuvieron presentes en los trabajos de Marx, y que su comprensión permita resignificar el lugar que en estos momentos ocupa dentro de los estudios de la antigüedad. Resignificación que sólo es posible siempre y cuando se observe cómo el teórico alemán procedía en sus investigaciones. No hay que olvidar su cuidadoso uso de categorías para sus trabajos, pues ellas constituyen herramientas para interpretar determinada realidad. La explicación de estos aspectos constituye la primera parte del presente.

Igualmente, el método que Marx hereda de Hegel, pero que constituye al mismo tiempo una superación (Aufhebung), es la clave para entender el concepto de clase social, por lo que su desvelamiento corresponde a la segunda parte del trabajo que el lector tiene en sus manos.

Por último, su concreción respecto de las sociedades antiguas, a través del método dialéctico, es lo que permite vislumbrar las relaciones entre los conceptos clase social y otros, como órdenes, status, etc. A esta tarea se dedica la tercera parte.

No está de más tener presente que el sistema elaborado por Marx respecto de las sociedades antiguas no debe ser aceptado sin más, sobre todo cuando las investigaciones están más adelantadas respecto del siglo XIX. El objetivo principal es despejar ciertos mitos y falsas interpretaciones para permitir esa resignificación que se mencionó anteriormente.

\section{La comprensión de las dificultades metodológicas en el uso de conceptos}

En el año de 1923, cuando Georg Lukács publicó Historia y Consciencia de Clase, no se conocían tres textos fundamentales para comprender la evolución intelectual de Marx: David Riazanov divulga La ideología ale- 
mana en 1932, año en que aparece también los Manuscritos de París de 1844, es decir, una década después del primero; en 1939, se publican los Grundrisse, o Elementos fundamentales para la crítica de la economía política, es decir, 16 años después del libro de Lukács. Si bien es cierto que buena parte de las complejidades de Lukács en esa época se fundamentan en desconocer esas obras, no es de menor valía reconocer que fue capaz de comprender metodológicamente cómo interpretar las sociedades precapitalistas partiendo de los textos de Marx hasta el momento disponible.

En aquel trabajo Lukács (1985). afirmó: "si ahora consideramos el materialismo histórico como método científico, es obvio que se puede aplicar también a épocas anteriores, previas al capitalismo. [...] Pero al aplicar el materialismo histórico a épocas precapitalistas se manifiesta una dificultad metodológica esencial e importante, la cual no aparece cuando se le aplica a la crítica del capitalismo" (p. 161). La dificultad que advierte el húngaro estriba en la "diferencia estructural" entre las sociedades capitalistas y las que le preceden. El capitalismo, en cuanto sistema, es un producto histórico, por lo que las categorías que de él surgen contienen ya la condena de ser también producto de la historia. Si se olvida la historicidad de las categorías económicas, se cae en el mismo reproche que le ha hecho Lukács (1985) al marxismo vulgar: "Su aplicación del materialismo histórico ha caído en la misma trampa que Marx señaló a propósito de los economistas vulgares, a saber: ha tomado categorías puramente históricas -y precisamente, como la economía vulgar, categorías de la sociedad capitalista- por categorías eternas" (p. 169).

Como se observa, Lukács nos advierte de las dificultades metodológicas de la aplicación de la concepción materialista de la historia respecto de las formas precapitalistas; no obstante, es posible subsanar tales escollos si se atiende al método desarrollado por Marx.

Ahora, es un hecho conocido que el teórico alemán no desarrolló de manera sistemática sus estudios sobre la antigüedad; es más, sus investigaciones sobre las sociedades clásicas están mediadas por la comprensión de la sociedad capitalista. No obstante, está al día con las fuentes literarias en su idioma original, sea griego o latín, además de los trabajos hasta el momento disponibles. El que aún sea de utilidad la obra de Marx sobre las sociedades precapitalistas (a pesar de los contrastes entre los materiales disponibles en aquella época y la nuestra) se debe, como lo ha señalado 
Fernández (1978), a la "genialidad de sus conceptos y de su método [que] le permitió utilizar los escasos materiales existentes con una eficacia y provecho muy superiores a la de sus contemporáneos, e incluso muy superior a la de historiadores que han podido gozar de unos medios y de un tiempo de los que no pudo gozar" (1978, p. 47).

El que Marx haya hecho un marcado acento en su estudio sobre el capitalismo, en contraste al que dedicó a la Antigüedad, es un aspecto fundamental y no un infortunio. Para él, la "economía burguesa nos suministra la clave de la economía antigua" (Manzano, 1998). Es precisamente con el capitalismo el que se ha podido comprender de una manera sistemática las relaciones sociales de la antigüedad. Pero, al llegar a este punto, hace una primera advertencia metodológica: "aunque sea cierto que las categorías de la economía burguesa encierran una verdad para todas las otras formas de sociedad, esto debe entenderse cum grano salis. Pueden contener estas categorías desarrolladas, anquilosadas, caricaturizadas, etc., pero siempre con una diferencia esencial” (Fernández, 1978).

Las "categorías son [...] formas de existencia, y con frecuencia, sólo aspectos aislados para expresar esta determinada sociedad" (Fernández, 1978 y Marx, 1971)²; por lo tanto, tomar las categorías económicas de la sociedad capitalista, que expresan relaciones de la sociedad capitalista, para interpretar formas de sociedad que le preceden no puede más que conducir a un falseamiento, a un desfiguramiento de las verdaderas relaciones históricas. En ese sentido, es posible encontrar categorías económicas en la antigüedad que aún permanecen en la sociedad burguesa, pero la historia ha variado sus relaciones internas, bien para atrofiarse, bien para desarrollarse (Fatas, 1978 y Fernández, 1978)². De allí, que Marx proceda con cuidado desde el punto de vista conceptual.

\footnotetext{
${ }^{1}$ Igualmente sentencia: "La sociedad burguesa es la organización histórica más desarrollada y múltiple de la producción. Las categorías que expresan sus relaciones y la comprensión de su estructura nos proporcionan, al mismo tiempo, un concepto de la estructura y las relaciones de producción de todas las demás formas de sociedad ya desaparecidas, sobre cuyas ruinas y con cuyos elementos se construye aquella y en la que vemos todavía residuos no superados que arrastra de las anteriores, simples síntomas que pueden desarrollarse en su significación, etc."

2 "Las categorías económicas no constituyen más que expresiones teóricas, abstracciones de las relaciones sociales de producción"

${ }^{3}$ Ejemplo de ello es el concepto de esclavitud, que varía en el modo de producción esclavista (Antigüedad) que en el modo de producción capitalista (presente en Estados Unidos y otros países, como Brasil).
} 
Tomemos la advertencia que realiza Marx respecto de la categoría de capital en la antigüedad: "En el concepto de capital está contenido el capitalista. Sin embargo, este error no es tan grande como el de, por ejemplo, todos los filólogos, que hablan de capital en la antigüedad, de capitalistas griegos, romanos. Esto no es más que otra expresión para decir que el trabajo en Roma y Grecia era libre, lo cual estos señores difícilmente podrán afirmarlo" (1977, p. 467).

No obstante, se ha seguido afirmando la existencia del capital en estas sociedades precapitalistas: sólo como ejemplo recuérdese la obra de Meyer (1982) y su discípulo (comunista) Rosenberg (2006), quienes tienen repletos sus trabajos no sólo con esta categoría, sino de otras como burguesía y proletariado ${ }^{4}$, etc. (Rosenberg, 1926).

El estudio de Marx sobre las sociedades precapitalistas en los Grundrisse (recuérdese que dedicó un aparatado con el nombre de Formen die der Kapitalistischen Produktion vorhergehen) tienen un propósito: establecer los presupuestos y las condiciones históricas, tanto del trabajo asalariado como del capital, fundamento de las relaciones sociales capitalistas. Pues bien, en ese estudio, el teórico alemán encuentra que la separación del trabajo asalariado con sus condiciones objetivas de realización es un proceso histórico que originariamente presenta una identidad entre el trabajador y tales condiciones objetivas (el trabajador se relaciona con la tierra como con su propiedad, y no como algo externo o extraño). Al arrancar el análisis desde esta identidad originaria, que el trabajo va separando cada vez más, encuentra que en las sociedades antiguas, donde la base de la ordenación económica es la propiedad de la tierra y la agricultura, la "finalidad económica es la producción de valores de uso, la reproducción del individuo en determinadas relaciones con su comunidad, en las que él constituye la base de la comunidad misma" (Marx, 1977)5. Es natural que en estas sociedades la finalidad económica sea la del mantenimiento de la comunidad misma, pero que,

\footnotetext{
${ }^{4}$ Eduard Meyer llega demasiado lejos al respecto: compara la Grecia homérica con la Edad Media, y la Grecia clásica con los tiempos modernos.

${ }^{5}$ Para el manuscrito Formen die der Kapitalistischen Produktion vorhergehen, que hace parte de los Grundrisse, se usará ésta edición. Para el Manuscrito M, o la Introducción a la Crítica de la economía política, usaremos la traducción de Wenceslao Roces.
} 
al mismo tiempo, su misma reproducción implica, la disolución de relaciones sociales que le dieron origen.

No se está negando el papel, e incluso, la importancia del valor de cambio en estas sociedades, sino que existe una dominancia del valor de uso (González, 1978). Visto más de cerca, para Marx (1970), el "proceso de cambio de las mercancías no aparece originariamente en el seno de las comunidades primitivas, sino donde éstas terminan: en sus fronteras, en los raros puntos de contacto con otras comunidades. Allí empieza el comercio, y de allí se extiende al interior de la comunidad sobre la que obra a modo de disolvente" (p. 74). Al respecto, los neomarxistas italianos ligados al Instituto Gramsci de mediados de los años 70 concibieron que en la antigüedad predominaba el valor de uso sobre el valor de cambio, pero, al mismo tiempo, encontraron procesos de acumulación de capital en forma limitada durante ciertos períodos de la historia (Duplá, 2001).

Si nos atenemos a la estructura propia de la mercancía, no sólo hay una predominancia del valor de uso, sino que, incluso, la propia estructura del valor de cambio se presenta dentro de los límites del valor de uso inmediato ${ }^{6}$ (Lukács, 1985). El valor de cambio puede existir, pero toda la producción está destinada no al cambio, cualquiera que sea su manifestación, sino directamente al consumo. En la medida en que la producción desborde el consumo, y sea la finalidad de las sociedades la producción de mercancías, no es posible encontrar como elemento de punto de partida esta forma de objetivación del trabajo.

Avanzando en otras categorías más concretas, es un hecho cierto la existencia del dinero en la Antigüedad (recuérdese las críticas peyorativas de Creonte en Antígona: "Ninguna institución ha surgido peor para los hombres que el dinero. Él saquea las ciudades y hace salir a los hombres de sus hogares. Él instruye y trastoca los pensamientos nobles de los hombres para convertirlos en vergonzosas acciones. Él enseñó a los hombres a cometer felonías y a conocer la impiedad de toda acción. Pero cuantos por una recompensa llevaron a cabo cosas tales concluye-

\footnotetext{
${ }^{6}$ Igualmente, Lukács afirma: "la forma del tráfico de mercancías en las sociedades precapitalistas es incapaz de ejercer influencia alguna en la estructura básica de la sociedad; se mantiene en la superficie, sin poder dominar el proceso de producción mismo, especialmente sus relaciones de trabajo".
} 
ron, tarde o temprano, pagando un castigo" [Sófocles, 2008]), pero la "mera existencia del patrimonio monetario y la obtención por éste de una clase de supremacía no es suficiente en modo alguno para que (...) resulte en capital"7 (Marx, 1970). Por demás, el dinero no adquiere la dimensión universal de cambiarse por fuerza de trabajo para "reproducir y valorizar el dinero, para ser consumido por el dinero como valor de uso no para la satisfacción de un placer, sino como un valor de uso para el dinero" (p. 427). El dinero jamás permeó ni dominó todas las relaciones sociales. El venezolano Silva (1976) lo expresa en estos términos: "Es cierto que en la antigüedad, en la época helenística, cundía el grito siguiente: jchremata aner!, o sea: su dinero es el hombre; pero nunca como ahora la relación monetaria había penetrado hasta los últimos intersticios de la mente humana" (p. 198).

Incluso, falta el aspecto más importante para que el capital adquiera las características de una relación social predominante: Marx advierte que Aristóteles (Finley, 1981 y Borisonik, 2013) ${ }^{8}$ había tropezado al analizar la forma del valor, por el hecho de no encontrar en las mercancías la forma equivalencial, pues, el trabajo humano abstracto no se encuentra plenamente desarrollado al existir "desigualdades entre los hombres y sus fuerzas de trabajo" (Marx, 1987, p. 26). Sólo la separación progresiva y abismal del trabajador con sus condiciones objetivas deja a éste únicamente con la fuerza de trabajo, que debe vender para poder existir. Ahora, el teórico de Trier analiza con detenimiento las condiciones para que el dinero se convierta en capital: es la necesaria e ineludible compra y venta de la fuerza de trabajo lo que permite esta metamorfosis. Al respecto afirma: "El capital sólo surge allí donde el poseedor de medios de producción y de vida encuentra en el mercado al obrero libre como vendedor de su fuerza de trabajo, y esta condición histórica envuelve toda una historia universal" (Marx, 1987, p. 123). Las últimas palabras de Marx son de gran valía: no hay que olvidar el concepto de historia, y el papel que ocupa en su concepción (Marx \& Engels, 1968). En esa línea, la constitución del trabajo asalariado y capital

\footnotetext{
${ }^{7}$ Palabras seguidas afirma: "De lo contrario la vieja Roma, Bizancio, etc., habrían acabado su historia con trabajo libre y capital o habrían más bien empezado otra".

${ }^{8}$ La interpretación de Marx sobre el análisis de Aristóteles a propósito del valor presenta grandes diferencias respecto de otros autores.
} 
como categorías económicas determinantes es un proceso socioeconómico para nada espontáneo, donde los aspectos económicos, por supuesto, juegan un papel fundamental.

Realizada la anterior advertencia del propio Marx, con agria crítica afirma: "En algunas enciclopedias de la Antigüedad clásica puede leerse el absurdo de que en el mundo antiguo estaba ya plenamente desarrollado el capital, "con la sola diferencia de que no existían obreros libres ni crédito. También el señor Mommsen incurre, en su Historia de Roma, en un quid pro quo tras otro" (Marx \& Engels, 1968). Como se percibe, la crítica implacable de Marx va dirigida a este modernismo que considera la existencia del capital como una categoría económica plenamente desarrollada, tal como se encuentra en el capitalismo.

En general, lo que encontramos es que para Marx sí existe una diferencia esencial entre sociedades capitalistas y precapitalistas (Lukács, 1985), y que el uso de categorías propias del capitalismo aplicado a las sociedades que le preceden implica un grave anacronismo. Pero esta diferencia no presupone una oposición infranqueable. Recuérdese que la sociedad burguesa en Marx (1977) se erige sobre formas de organización del pasado, las cuales, continúan subsistiendo en esta forma desarrollada. Además, tomar las categorías económicas sin su historicidad conlleva a un grave riesgo, no sólo para develar las relaciones históricas de la antigüedad sino también para la superación del modo de producción capitalista: en su devastadora crítica a Proudhon, el teórico alemán advierte el error de los economistas: las categorías que expresan relaciones sociales capitalistas las hacen pasar por naturales, como sujetas a leyes de la naturaleza, y por tanto, son "leyes eternas que deben regir siempre la sociedad" (Marx, 1971).

\section{Los niveles de abstracción y el concepto de clases en el método de Marx}

El concepto de clase social en Marx presenta, entre otras dificultades, el que este autor no le haya dado un tratamiento sistemático (Gurvitch, 1960) ${ }^{9}$; cuando se dispuso a realizarlo, en el Tomo III de $E l$

\footnotetext{
${ }^{9}$ Esto ha traído grandes confusiones, por ejemplo, la de Gurvitch, tal como se demostrará más adelante.
} 
Capital, la muerte obligó a dejar interrumpido el manuscrito. El capítulo "Las clases" (LII), por demás, tiene la siguiente afirmación: "Los propietarios de simple fuerza de trabajo, los propietarios de capital y los propietarios de tierras, cuyas respectivas fuentes de ingresos son el salario, la ganancia y la renta del suelo, es decir, los obreros asalariados, los capitalistas y los terratenientes, forman las tres grandes clases de la sociedad moderna, basada en el régimen capitalista de producción"(Marx, 1987). Ahora, ¿no contradice esto el hecho que el fundamento de la sociedad burguesa sea la contradicción entre el trabajo asalariado y el capital, categorías económicas que personifican los obreros asalariados y los capitalistas, consecuentemente?

A raíz de no haber hecho una exposición sistemática, ni tener presente el método dialéctico, el concepto de clase social ha sido tratado de las más diversas maneras. Pero, en algo tiene razón Gurvitch (1960): el que "Marx, a diferencia de sus epígonos, hacía del concepto de clase un punto de partida para análisis concretos de una estructura y no una llave capaz de abrir todas las puertas" (p. 17). No obstante, este acierto del ruso no le blinda de su incomprensión del concepto.

Entre otras críticas, Gurvitch (1960) encuentra una diversidad de clases sociales en las obras de Marx:

En la primera serie de obras [se refiere Gurvitch desde las Obras de juventud hasta la Miseria de la filosofía], el problema es estudiado desde el punto de vista de la filosofía de la historia y de la sociología, en una suerte de recíproca rivalidad. En la segunda serie [se refiere a las obras Revolución y contrarrevolución en Alemania, Las luchas de clases en Francia, El dieciocho brumario de Luis Bonaparte y La guerra civil en Francia], la cuestión es tratada bajo un ángulo propiamente histórico y concreto (división en clases y compromisos temporarios entre éstas en función de circunstancias) con aclaraciones provenientes ya de la sociología, ya de la filosofía. En la tercera serie [se refiere a los tres tomos de El capital] Marx sigue el movimiento de las clases en el cuadro del funcionamiento y de las contradicciones de la economía capitalista, que deben conducir rápidamente a su derrumbamiento. Se observará que lo que persiste en particular a través de estos tres géneros de análisis es la lucha entre la sociología y la filosofía de la historia en el pensamiento, tan profundo, de Marx concerniente a las clases sociales (p.27). 
Luego de una copiosa revisión de las obras de Marx al respecto, Gurvitch (1960) llega entre otras conclusiones, a la siguiente: "Marx distingue para el presente cinco clases: I: propietarios terratenientes, II: burgueses, III: pequeños burgueses, IV: granjeros-campesinos, V: proletarios. Pero cree que estas clases se reducirán a dos" (p. 38).

Según Gurvitch, Marx no tendría un concepto claro sobre las clases sociales, mostrando una variedad de clases que se superponen unas a otras, en un universo teórico caótico, confuso y abigarrado. Hecho que parece confirmarse con la cita anterior de El Capital, cuando se refiere a tres clases sociales: burguesía, terratenientes y proletariado.

Otra crítica al concepto de clase de Karl Marx proviene del sociólogo Ossowski (1972): para este autor, el teórico alemán tendría diversos esquemas para analizar la sociedad, distinguiéndose el dicotómico, el de gradación y el funcional. En el primero, las clases sociales se reducen a dos correlativas y contrapuestas (1972, p. 42); en el segundo, la sociedad es estratificada en tres o más clases sociales, de acuerdo con su ubicación superior o inferior (p. 45); en el tercer esquema, la sociedad se analiza de acuerdo con las funciones en la vida social (p. 77).

Si en Gurvitch el abigarrado universo de clases sociales en la obra de Marx se debía a no tener claridad sobre él, en Ossowski (1972), ello se debe a la finalidad de sus escritos: como revolucionario, prevalece la concepción dicotómica, como sociólogo, el de gradación, y como economista, el funcional (p. 107).

Para comprender si existen dos, tres o más clases, Harnecker (1976), por su parte, se pregunta: “¿a qué nivel de abstracción se sitúa Marx cuando habla de estas tres clases? ¿Al nivel abstracto del modo de producción puro o al nivel más concreto de una formación social con marcada dominancia capitalista?" (1976, p. 171). La pregunta es fundamental para subsanar el presunto inconveniente, razón por la que se atenderá los niveles de abstracción que maneja Marx a la hora del análisis para situar en él su concepto de clase social, pues, como ha indicado Dos Santos (1967), la "rigurosa diferenciación e interdependencia entre los niveles de abstracción es uno de los principales aspectos del método dialéctico"(p. 141). ${ }^{10}$

${ }^{10}$ No se pretende abordar la complejidad del método de Marx, sino relacionarlo en los niveles de abstracción. 
Si bien no se pretende un desarrollo exhaustivo del método de Marx, sí hay que indicar aquello que está íntimamente relacionado con los niveles de abstracción que se encuentran presentes en sus obras.

Marx comienza El Capital con la relación más simple, la que igualmente se presenta en formas de sociedad no desarrolladas: la mercancía. Luego, procede a analizarla en sus dos lados diferenciados, estudiados cada uno separadamente, del que se "desprende su relación recíproca y su interacción. Nos encontramos con contradicciones, que reclaman solución. [...] Y si estudiamos el carácter de esta solución, veremos que se logra creando una nueva relación, cuyos dos lados contrapuestos tendremos que desarrollar ahora, y así sucesivamente" (Engels, 1955).

Al estudiar la mercancía, ésta se presenta como valor de uso y como valor de cambio. Al analizar el valor de cambio, hace abstracción del valor de uso, separa lo secundario para detenerse en lo principal: "si prescindimos del valor de uso de las mercancías, éstas sólo conservan una cualidad: la de ser productos del trabajo" (Marx, 1987). No interesa en lo más mínimo la materialidad de la mercancía, sino el ser productos del trabajo humano abstracto. Esta misma forma de proceder se encuentra en todas las demás categorías que analiza, v. g., la forma simple, concreta o fortuita del valor, la forma total o desarrollada del valor, etc. Las relaciones sociales que se presentan ante el observador como un conjunto caótico al momento del análisis, por medio de la abstracción, va llevando a categorías que debe separar en sus elementos fundamentales, arrojándole así categorías más simples, diversificando la unidad; es por esto que afirma que lo "concreto es concreto porque constituye la síntesis de muchas determinaciones y, por lo tanto, la unidad de lo múltiple" (Marx, 1985).

La abstracción ya había sido defendida por el pensador alemán en el Prólogo de la primera edición de El Capital: "En el análisis de las formas económicas de nada sirven el microscopio ni los reactivos químicos. El único medio que disponemos, en este terreno, es la capacidad de abstracción" (Marx, 1987).

método dialéctico que Marx usa para la economía política (desde luego, no se agota allí) está íntimamente ligado a los niveles de abs- 
tracción, y no se reduce éste a la forma lógica ${ }^{11}$ en el análisis de las categorías económicas, sino que este aspecto lógico, puro, se nutre constantemente de la historia, por lo que, en Marx, la abstracción también está presente en otro tipo de estudios. (Engels, 1955)

Respecto de los niveles de abstracción, Dos Santos (1967) ha identificado cuatro niveles, y es allí donde debemos ubicar el concepto de "clase social" (1967, 144):

- Modo de producción: en este primer nivel, la categoría de clase social está directamente relacionado al análisis del modo de producción. Aquí, el "concepto de clases aparece como resultado del análisis de las fuerzas productivas [...] y de las relaciones de producción" (ibíd., p. 91). La lucha de clases se presenta relacionada con "la superación de una determinada formación social (modo de producción más modo político y cultural)" (ibíd., p. 92). Es un análisis de las clases desde un nivel abstracto, que parte de la realidad histórica real, pero que no se presenta de forma pura en ninguna realidad histórica. La necesidad de estudiar la realidad en un nivel más concreto es lo que conlleva a la negación de las elaboraciones sistémicas de este nivel, ergo, surge otro nivel de abstracción.

- Estructura social: Las clases sociales, en este momento, varían de acuerdo a la sociedad, donde, aun presentándose el antagonismo del modo de producción dominante, coexiste con otras relaciones sociales. Esto implica que no sólo se presenten oposiciones entre la relación determinante, sino otras históricas. A diferencia del análisis en el primer nivel de abstracción, no se trata de las relaciones sociales posibles, o de tendencias, sino realmente existentes.

- Situación social: este tercer nivel concreta aún más el análisis, pero no presenta las relaciones en términos empíricos, sino científicos. Resalta en este nivel que el concepto de clase social hace uso de los sistemas de estratificación, que no pocas veces se presenta como un momento unilateral, sin que por ello se niegue su consideración como clase. Los individuos reales pueden ser clasificados en las categorías que arroje éste tipo de análisis.

\footnotetext{
${ }^{11}$ No obstante, no hay que olvidar que el método lógico "necesita ilustrarse con ejemplos históricos, mante-
} nerse en contacto con la realidad": 
- La coyuntura: éste último nivel de abstracción presenta una riqueza conceptual mucho más rica, por cuanto la estructura de clase varía a medida que varían las contradicciones en el seno de la sociedad.

El capitalismo, en su forma pura, lógica, (pero que parte de la realidad material, de lo real y concreto [Marx, 1985]), se presenta como un concreto representado, y en ese análisis, la tendencia de las contradicciones es a separar cada vez más el trabajo asalariado y el capital, a "convertir el trabajo en trabajo asalariado y los medios de producción en capital" (Marx, 1987). En ese sentido, para Marx, las contradicciones sociales, la lucha de clases, se presenta entre los trabajadores asalariados y los capitalistas, personificaciones económicas de relaciones sociales.

Ahora, el capitalismo no es posible encontrarlo en su forma pura en ninguna formación socioeconómica, pues la historia ha hecho posible que con las relaciones capitalistas subsistan otro tipo. Allí donde la relación entre trabajo asalariado y capital se presenta como la relación principal, es posible encontrar ciertas tendencias de El capital, pero sin que por ello, se nieguen relaciones previas y no capitalistas. Por esta razón, es necesario llevar a cabo una concreción en el análisis. Y es aquí el momento para ubicar ese trinomio conceptual de burguesía, proletariado y terratenientes. En realidad, cuando habla de estas tres clases, lo hace refiriéndose al país inglés: "Es en Inglaterra, indiscutiblemente, donde más desarrollada se halla y en forma más clásica la sociedad moderna, en su estructuración económica. Sin embargo, ni aquí se presenta en toda pureza esta división de la sociedad en clases. También en la sociedad inglesa existen fases intermedias y de transición que oscurecen en todas partes [...] las líneas divisorias. Esto, sin embargo, es indiferente para nuestra investigación" (Marx, 1987).

Si bien en un análisis del modo de producción las dos clases antagónicas corresponden a proletariado-burguesía, producto de la tendencia que personifican (trabajo asalariado y capital), el terrateniente es una clase en un nivel de abstracción mucho más concreto.

En este sentido, la crítica de Gurvitch (1960) y Ossowski (1972) a Marx no deja de ser una incomprensión sobre su método, sobre todo, de los niveles de abstracción al momento de analizar las sociedades 
históricas. Al ruso le parece claro la "pluralidad de clases, por lo menos virtuales, en el interior del régimen capitalista" (Gurvitch, p. 57). El autor alemán siempre estuvo consciente de una armonía, cuyas diferenciaciones son producto de concreciones, ante la cual Gurvitch se aterra y no logra entender, razón por la cual ve superpuestas las clases sociales.

\section{¿Clases sociales o status en la antigüedad romana?}

Ya se ha visto cómo las clases sociales, desde el método dialéctico de Marx se desarrollan en niveles de abstracción, así como se ha advertido sobre las dificultades metodológicas que supone el uso de conceptos modernos a sociedades precapitalistas. Ahora, ¿es lícito el uso de este concepto para la sociedad antigua?

Autores como Finley (2003) se han pronunciado en contra del uso del concepto de clase social en la antigüedad ${ }^{12}$ (p. 84). Sus alternativas conceptuales son las categorías de órdenes y status: por un lado, un "orden o posición es un grupo jurídicamente definido que forma parte de una población, con privilegios e incapacidades en uno o más campos de actividad gubernamental, militar, jurídica, económica, religiosa, marital, y que se halla en una relación jerárquica con otros órdenes" (p. 78); por el otro, el status queda reservado a las "situaciones jurídicamente no definidas y en el que la situación social, económica, política, etc., de los individuos rebasa el mero marco jurídico de los órdenes" (González, 1978, Finley 2003).

Las críticas al concepto de Marx de clase social, al ser aplicado a la antigüedad, parten, en realidad, de la incomprensión de su método. Al preguntarse ¿qué es una clase social?, Pierre Vidal-Naquet responde: "1. Una clase social es un grupo de hombres que ocupan un lugar muy definido en la escala social. [...] 2. Una clase social ocupa un lugar de-

\footnotetext{
${ }^{12}$ La obra de Finley tiene una fuerte inspiración del alemán Max Weber. El último distingue entre sociedad estamental y clasista; dependiendo a la primacía de su articulación social, así será el carácter de esta sociedad. A pesar de esto, Finley 10 años después, usa el término de clase, pero, "como hacemos de ordinario en el lenguaje corriente", criticando esa "mala costumbre" de etiquetar como marxista al que en los análisis históricos haga uso de este concepto. Es un concepto ligero, y no marxista. (Finley, 1986). La ligereza del concepto de clase social en Finley: "Hay contextos en que, por ejemplo, es inofensiva una referencia imprecisa a las clases: yo mismo hablo de las "clases altas" de esta manera, cuando confío en que el significado es inequívoco".
} 
finido en las relaciones de producción: ésa es la aportación principal del marxismo y es inútil insistir sobre la misma [cursivas de los autores] [...] 3. Finalmente, una clase social supone la toma de consciencia sobre los intereses que le son comunes, el empleo del lenguaje común, una acción común en el juego político u social. Esto también se lo debemos a Marx (1977) [se refiere al Dieciocho brumario de Luis Bonaparte]" (1977, p. 19).

Pero el teórico alemán, al hacerse el mismo interrogante que VidalNaquet dice: "La contestación a esta pregunta se desprende enseguida de la que demos a otra: ¿qué es lo que convierte a los obreros asalariados, a los capitalistas y a los terratenientes en factores de las tres grandes clases?" (Marx, 1987). Si bien es cierto que cuando intenta responder la pregunta, interrumpe el manuscrito por su muerte, no es de menor valía el que Marx critica la apariencia de estar relacionadas única y exclusivamente con las rentas y sus fuentes de renta. Con gran sátira afirma:

Es cierto que desde este punto de vista también los médicos y los funcionarios, por ejemplo, formarían dos clases, que pertenecen a dos grupos sociales distintos, cuyos componentes viven de rentas procedentes de la misma fuente en cada uno de ellos. Y lo mismo puede decirse del infinito desperdigamiento de intereses y posiciones en que la división del trabajo social separa tanto a los obreros como a los capitalistas y a los terratenientes, a estos últimos, por ejemplo, en propietarios de viñedos, propietarios de tierras de labor, propietarios de bosques, propietarios de minas, de pesquerías, etc. (Marx, 1987).

Por eso se equivoca Pierre Vidal-Naquet al reducir el concepto de clase social (en el sentido que le da Marx) a las relaciones de producción. El mismo error comete Finley (2003) cuando afirma:

$\mathrm{Ni}$ aun el concepto marxista de clase, aparentemente claro e inequívoco, deja de tener sus dificultades. Se clasifica a los hombres por su relación con los medios de producción, en primer lugar entre aquellos que poseen y aquellos que no poseen medios de producción; en segundo lugar, los primeros son divididos entre los que trabajan y los que viven del trabajo de otros. Sea cual fuere la aplicabilidad de tal clasificación a la sociedad actual, para el historiador de la antigüedad presenta una dificultad obvia: el esclavo y el jornalero libre resultan entonces, según una interpretación mecánica [cursivas fuera de texto], miembros de la misma clase, como también el más rico de los senadores y el ocioso propietario de una pequeña alfarería (p. 84). 
Por esta razón, "ni desde la perspectiva marxista ni desde la no marxista es la clase una categoría suficientemente delimitada para nuestros propósitos" (Finley, p. 84).

Esa interpretación mecánica de Finley que se le acusa a Marx es completamente ajena a él, como ya se ha mostrado anteriormente al explicar los niveles de abstracción; en nada afecta a su método las diferentes interpretaciones de su obra, la mayoría de las veces, reduccionistas. Por eso Vidal-Naquet hace una lectura ligera y poco profunda cuando afirma que una clase se define por el lugar en las relaciones de producción. Pero su error no es tan grande como el creer que es inútil profundizar sobre el aporte del autor alemán. Vidal-Naquet acierta al considerar que una clase social ocupa un lugar definido en las relaciones de producción, pero su interpretación de ser la única forma de comprender el concepto, en el nivel abstracto, le conduce a la equivocación.

Como se ha venido demostrando, el concepto de clase social (desde Marx) se resuelve en el modo de producción mismo, en términos abstractos, pero no se limita a esta abstracción: la búsqueda de concretar el análisis conlleva a negar los conceptos en ese estado puro, a esas "tendencias" a las que se refiere Marx en El Capital (1987).

El concepto de status de Finley es extremamente útil para comprender relaciones mucho más concretas en las sociedades antiguas, pero la dificultad está en superponer la estratificación social al concepto de clase social, en negar la existencia del segundo por la afirmación del primero. Con justeza ha dicho González (1978): "las fracciones, los estratos y las categorías no están "fuera" o "al lado" de las clases sociales, sino que ellas mismas forman parte de las clases, y ello en función de que las clases no constituyen un todo uniforme y homogéneo" (p. 37). Este todo heterogéneo debe ser comprendido, inicialmente, en el sentido estricto de González Román, es decir, en lo referente a un nivel de abstracción donde surgen las estratificaciones sociales; no obstante, hay que ampliar esta afirmación de la heterogeneidad también respecto de las formas como surgen en el análisis las relaciones sociales. Es, para parafrasear a Marx, la unidad de lo diverso, cuando se comprende las determinaciones más ricas en la 
abstracción y su inmanente concreción. La afirmación de González Román es otra forma de determinar lo que se ha mostrado respecto desde los niveles de abstracción.

Que el concepto de clase social, en su sentido científico, haya surgido precisamente con el capitalismo, no es pura casualidad. Para explicar esto, hay que partir de la diferencia esencial entre las sociedades capitalistas y las precapitalistas.

Respecto de las sociedades precapitalistas, ha dicho Lukács (1975) que las

formas jurídicas tienen que penetrar constitutivamente en las relaciones económicas. En estas sociedades no hay categorías económicas puras [...]. Sino que las categorías económicas y las categorías jurídicas están materialmente, por su contenido, inseparablemente entrelazadas [...] Dicho hegelianamente: la economía no ha alcanzado tampoco objetivamente en esas sociedades el estadio del ser-para-sí, y por eso no es posible, en el seno de una tal sociedad, una posición a partir de la cual pueda hacerse consciente el fundamento económico de todas las relaciones sociales (p. 123).

En las sociedades capitalistas, la situación es muy distinta: la "burguesía y el proletariado son las únicas clases puras de la sociedad burguesa, esto es: ellas son las únicas cuya existencia y cuyo desarrollo se basan exclusivamente en el desarrollo [sic] del proceso de producción moderno" (Lukács, 1985). De allí, que Marx se dedicara a develar con un marcado acento las relaciones económicas, sin que por ello negara otro tipo de determinaciones en las relaciones sociales.

Esa unidad entre las formas jurídicas y económicas en las sociedades precapitalistas se presenta como apariencia, como el encubrimiento que precisamente hay que develar: "en realidad, toda ciencia estaría de más, si la forma de manifestarse las cosas y la esencia de éstas coincidiese directamente" (Marx, 1987, p. 757). Si bien la categoría clase social es un concepto moderno, el concepto en su forma científica tiene la impronta de Karl Marx. Hay que recordar que el propio autor reconocía que no era el primero en hacer uso del concepto, incluso, ni de su fisonomía: "Mucho antes que yo, los historiadores 
burgueses habían descrito el desarrollo histórico de esta lucha de clases, y los economistas burgueses la anatomía económica de las clases" (Marx, 1972, p. 56). Ahora bien, la cientificidad del concepto, y lo que distingue ésta concepción de otras está en no en considerar las clases sociales como grupos de individuos sino como fuerzas sociales internas, producto de una realidad histórica (González, 1978).

La categoría de clase social que ha trabajado el autor a lo largo de su obra pudiese parecer una interpretación arbitraria, pero el sistema que Marx construye es armónico. Esta armonía es perceptible cuando aparece el concepto de totalidad y la importancia que tiene en su pensamiento.

Que sea Georg Lukács, en 1923, a través de su trabajo Historia y consciencia de clase, quien recupere el lugar del concepto de "totalidad" dentro del pensamiento de Marx, luego del reformismo de la II Internacional, no es algo puramente casual y extraño (Vacca, 1978). La sentencia de Lukács es inequívoca: "La categoría de totalidad, el dominio omnilateral y determinante del todo sobre las partes, es la esencia del método que Marx tomó de Hegel y transformó de manera original para hacer de él el fundamento de una nueva ciencia" (Silva, p. 87).

Desde La miseria de la filosofía, Marx (1971) ha dado una importancia fundamental a este concepto. En su Tercera observación, donde analiza el método de Proudhon y expone de manera polémica el suyo, afirma: "Las relaciones de producción de cualquier sociedad forman un todo" (1971, p. 162). Es indicativa su crítica a Proudhon porque, según Marx, el pensador francés concibe las relaciones económicas como fases sociales, pero al analizarlas según lo que cree es el método dialéctico, una sola fase debe ser explicada a partir de las demás, sin que hayan cumplido la transición de una a otra (p. 162).

La forma como Marx (1977) analiza en El Capital las relaciones sociales es partiendo desde la totalidad. "El todo, tal como aparece en la mente como todo del pensamiento, es un producto de la mente que piensa y que se apropia del único modo posible" (1977, p. 24), que en el caso de la economía política, es la abstracción que reproduce en 
el pensamiento esos "concretos del pensamiento" que se manifiesta como "totalidad concreta" (p. 24). Este punto es interpretado por Ludovico Silva con precisión meridiana: "De ahí la enorme importancia del concepto de totalidad dentro de la ciencia social marxista. Se parte de una totalidad teórica, para llegar a la totalidad práctica. Se parte, por ejemplo, de la mercancía, para llegar a las clases sociales, que son, por cierto, el alfa y el omega de El Capital, al menos en el estado en que dejó después de la muerte su autor" (p. 204).

Respecto de las clases sociales, la categoría de totalidad es de vital importancia. Las relaciones sociales constituyen un todo de la sociedad, que parten, desde luego, de una primacía de las relaciones que le permiten hacer historia (Marx \& Engels, 1975, p. 28). Pero, que sean exclusivamente económicas las relaciones sociales es un asunto completamente extraño a Marx. El mismo Engels (1973), en la famosa carta a J. Bloch, fechada el 21 de septiembre de 1890, intentó equilibrar la desproporción: "Según la concepción materialista de la historia, el elemento determinante de la historia es en última instancia la producción y la reproducción en la vida real. Ni Marx ni yo hemos afirmado nunca más que esto; por consiguiente, si alguien lo tergiversa transformándolo en la afirmación de que el elemento económico es el único determinante, lo transforma en una frase sin sentido, abstracta y absurda" (1973). Como se percibe, ese determinismo es ajeno a Marx, pero en un nivel del modo de producción, las clases se resuelven en ella, es decir, desde ese aspecto económico. A medida que se concretan los análisis, a medida que se hace evidente la necesidad de llevar a otro nivel de abstracción, o mejor, de concreción, las clases sociales pueden tomar otro tipo de terminaciones en cuanto a su estructuración. Lo que permite la abstracción en el primer nivel es comprender desde la totalidad el movimiento histórico, sujeto a relaciones económicas. El término de ideología es útil en este punto, tal como lo desarrolla Marx \& Engels (1968). El ideólogo (Marx), por su parte, cree que es la consciencia social lo que determina el proceso de vida real, y no a la inversa (Marx, 1970).

Las estratificaciones sociales, evidentemente existen, y se hacen palpables sobre todo al analizar las sociedades precapitalistas. Pero, 
ya ha señalado Lukács (1985) de manera inequívoca que la "consciencia estamental encubre la naturaleza del factor histórico real que tiene la consciencia de clase, impide que ésta llegue en general a manifestarse" (p. 124). Es ésta la razón por la que las categorías históricas se presentan en la antigüedad como estamentos y no se reconocen a sí mismos como clases, sin que por ello se perjudique un tipo de análisis que para interpretar la sociedades antiguas haga uso del concepto de clase social, de manera que explique la totalidad de las relaciones sociales, y de allí, ir concretando los análisis a formas más específicas. Las clases existen en la antigüedad, pero en el nivel del modo de producción se hayan entrecruzadas con categorías jurídicas que no permiten su distinción plena, y es el capitalismo quien supera esta forma de presentarse la totalidad histórica.

\section{CONCLUSIÓN}

Contrario a las interpretaciones que suelen hacerse de Marx, éste siempre tuvo presente la distinción entre sociedades capitalistas y precapitalistas, razón por la cual, las categorías que expliquen relaciones sociales deben tener un cuidadoso análisis. El autor critica el uso de categorías modernas para la antigüedad, por ejemplo, el concepto de capital. Por otro lado, el término clase social, lejos de los comentarios de sus críticos, se presenta como armónico siempre y cuando se tome en cuenta su método dialéctico. Los niveles de abstracción que usa en los análisis es la clave para comprender el movimiento histórico. Es allí donde hay que ubicar en el análisis las conceptualizaciones de las clases sociales desde la perspectiva del autor. Por último, es posible usar el concepto de clase social respecto de las sociedades precapitalistas siempre y cuando se manejen, por un lado, los niveles de abstracción en la interpretación, y, sobre todo, se entienda que en éstas, la consciencia estamental encubre la consciencia de clase, razón por la cual, las categorías históricas no pueden llamarse a sí mismas como clases sociales; por el otro, se tenga presente la importancia de la categoría de totalidad. 


\section{REFERENCIAS}

Borisonik, H. (2013). El debate moderno sobre los escritos económicos aristotélicos. En: Revista de Economía Institucional, 15, 28.

DOS SANTOS, T. (1967). El concepto de clases sociales. En: Anales de la Universidad de Chile, 1: 141-144.

Duplá, A. (2001). Notas a propósito de la historiografía neomarxista italiana sobre el mundo clásico. En: Studia Histórica. Historia Antigua, 1.

Engels, F. (1955). Contribución a la crítica de la economía política. En: Marx, C.; Engels, F. Obras escogidas en dos tomos. Vol. 1. Moscú: Editorial Progreso.

Engels, F. (1973). De Engels a Bloch. En: Marx, C; Engels, F. Correspondencia completa de C. Marx y F. Engels. 2, 486. Bogotá: Editor Rojo.

Fatas, G. (Febrero, 1978). Una propuesta metodológica. ¿Qué es una sociedad esclavista? En: Instituto de Historia Antigua. Actas del coloquio 1977. Estructuras sociales durante la antigüedad, 1, 1. Gijón.

Fernández, J. (Febrero, 1978). Explotación y esclavitud en la antigüedad, según C. Marx. En: Instituto de Historia Antigua. Actas del coloquio 1977. Estructuras sociales durante la antigüedad, 1, 1. Gijón.

Finley, M. (1981). Aristóteles y el análisis económico. En: M. Finley, et. al. Estudios sobre historia antigua. (37-64). Akal Editor: Madrid.

Finley, M. (1986). El nacimiento de la política. Barcelona: Editorial Crítica.

Finley, M. (2003). Economía de la antigüedad. México D.F.: Fondo de Cultura Económica.

González, C. (Febrero, 1978). Las clases sociales. ¿Un problema terminológico o ideológico en las investigaciones sobre la antigüedad? En: Instituto De Historia Antigua. Actas del coloquio 1977. Estructuras sociales durante la antigüedad, 1(1). Gijón.

Gurvitch, G. (1960). El concepto de clases sociales, de Marx a nuestros días. 2 ed. Buenos Aires: Ediciones Galatea - Nueva Visión.

Harnecker, M. (1976). Los conceptos fundamentales del materialismo histórico. 34 ed. Bogotá D.C.: Siglo Veintiuno Editores S.A.

Lukács, G. (1985). Historia y consciencia de clase. 1. Barcelona: Ediciones Orbis, S.A. 
Manzano Moreno, E. (1998). Relaciones sociales en sociedades precapitalistas: una crítica al concepto «modo de producción». En: Hispania: Revista española de historia, 58 (200), 881-914.

Marx, C. y Engels, F. (1968). La ideología alemana. 2 ed. Montevideo: Ediciones Pueblos Unidos.

Marx, C. (1970). Contribución a la crítica de la economía política. Madrid: Alberto Corazón Editor.

Marx, C. (1971). Miseria de la filosofía. Madrid: Aguilar.

Marx, C. (1972). De Marx a Weydemeyer. En: Marx, C. y Engels, F. Correspondencia. Buenos Aires: Editorial Cartago.

Marx, C. \& Engels, F. (1975). La ideología alemana. Buenos Aires: Ediciones Pueblos Unidos.

Marx, K. (1977). Lineas fundamentales de la crítica de la economía política. (Grundrisse), I. Barcelona: Editorial Crítica.

Marx, C. (1985). Grundrisse. Lineamientos fundamentales para la crítica de la economía política 1857-1858, 1. México D.F.: Fondo de Cultura Económica.

Marx, C. (1987). El Capital. Crítica de la economía política, 1. 2 ed. Bogotá D.C.: Fondo de Cultura Económica.

Meyer, E. (1982). El Historiador y la historia antigua. México D.F.: Fondo de Cultura económica.

Ossowski, S. (1972). Estructura de clases y conciencia social. 2. ed. Ediciones Península: Barcelona.

Rosenberg, A. (2006). Democracia y lucha de clases en la antigüedad. España: El viejo Topo.

Rosenberg, A. (1926). Historia de Roma. Madrid: Revista de Occidente.

Ruiz Sanjuan, C. (2010). La articulación de lo abstracto y lo concreto en el proceso de conocimiento teórico. En: Éndoxa. Series filosóficas, 25.

Silva, L. (1976). Anti-manual para uso de marxistas, marxólogos y marxianos. Venezuela: Monte Ávila Editores.

Sófocles. (2008). Antígona. Barcelona: Editorial Gredos, S.A.

Sweezy, P. (1979). Teoría del desarrollo capitalista. México D.F: Fondo de Cultura Económica. 
Vacca, G. (Enero, 1978). Hegel en la historia del marxismo. En: Revista Dialéctica, 1 (4).

Vidal-Naquet, P. (1977). ¿Constituían los esclavos griegos una clase social? En: Mossé, C., et al. Clases y luchas de clases en la Grecia Antigua. Madrid: Akal Editor.

Weber, M. (2002). Economía y sociedad. 2 ed. México D.F.: Fondo de Cultura Económica. 